\title{
Polyoxyl 40 Hydrogenated Castor Oil
}

National Cancer Institute

\section{Source}

National Cancer Institute. Polyoxyl 40 Hydrogenated Castor Oil. NCI Thesaurus. Code C84090.

A polyethylene glycol derivative of hydrogenated castor oil where the average PEG chain length is 40 . PEG-40 hydrogenated castor oil is a nonionic surfactant used as an emulsifying and solubilising agent in pharmaceutical preparations and cosmetics. 